\title{
Governance and Management Support for Mathematical Literacy Teaching and Learning at a School in Mpumalanga Province of South Africa
}

\author{
Dr. M.G. Ngoepe \\ Prof. L.M. Kaino \\ Department of Mathematics Education, University of South Africa, South Africa \\ Emails: ngoepmg@unisa.ac.za; kainolm@unisa.ac.za
}

\section{Doi:10.5901/mjss.2014.v5n1p579}

\begin{abstract}
This paper reports on the findings of the study that assessed the capacity of the School Governing Body (SGB) and School Management team - SMT ( school principal, deputy principal and HODs) to support the teaching and learning of mathematics and science subjects at one school in Mpumalanga Province in South Africa. In this paper, only findings of the mathematical literacy component are reported and findings on the other subjects are reported in other papers. A case study was conducted in one FET school and used a mixed- methods research design whereby qualitative and quantitative data was collected. The learners were from Grades 10 to 12. The data was collected in the year 2012 from the SGB, SMT, school learners, teachers, and general assistants at the school. The findings showed that though the students were enthusiastic to learn mathematical literacy subject, the SGB and School Management comprised of a weak team to support the students in pertinent areas needed to master the subject. It was concluded that lack of communication between the school administration, SGB, teachers, students and parents on issues pertaining to the execution of school policies, activities and security, could have contributed to lack of students' engagement and assistance to master the subject.
\end{abstract}

Keywords: School governing body, School management, Governance and management support, mathematical literacy, teaching and learning.

\section{Introduction}

In order to provide the right environments for teaching and learning, all public schools in South Africa have School Governing Bodies (SGB) and these comprise of school parents, educators, learners and the principal. The aim of SGBS is to ensure that educators, parents, learners and non-teaching staff actively participate in the governance and management of schools with a view of providing the right environment for teaching and learning.

Since the establishment of the school governing bodies (SGB) in 1996, all public schools in South Africa are expected to have SGBs of elected members as part of their management and governance structures (RSA, 1996). The SGB comprises of school parents (who are the majority), educators, learners and the principal who is the ex-officio (Karlsson, 2002; RSA, 1996: section 23; Van Wyk, 2004); while the school management includes the principal, deputy principal and heads of departments or senior educators (Heystek, 2004). The rationale for the establishment of democratic structures of school governance is to ensure that educators, parents, learners and non-teaching staff actively participate in the governance and management of schools with a view of providing the right environment for teaching and learning (Van Wyk, 2004). The South African Schools Act Number 84 of 1996: sec 16, describes school management and governance as two separate teams with different responsibilities (Heystek, 2004). The first team is the professional management team, which is responsible for teaching and learning; and support activities; the second team is the SGB, which is responsible for the governance (strategic management) of the school.

The SGB is the strategic director of the education business at the school, while the school management is the implementer of the strategies recommended by the SGB. The school management is expected to maintain efficiency and effectiveness of the organisational arrangements at the school, such as the approved national curriculum and the welfare of learners, educators and support staff (RSA, 1996).The SGB has the responsibility of planning and budgeting; setting objectives; oversight; organising and staffing; and resource allocation to ensure that the school has skilled educators and support staff; to ensure that educators have the right environment to work in and adequate learning and teaching material to cover the national school curricula; management as the quality assurer; and to ensure efficient and effective use of 
resources for the development of young learners (RSA, 1996). The two teams share the responsibility for the total welfare and success of the school; and therefore they are interdependent of each other because of the nature of their membership composition. Their relationship is therefore one of the most significant variables that determines success in their roles and the school performance (Bush and Heystek, 2003).

Having said that, both the SGB and the school management need to have the required capacity, leadership and managerial skills because the performance of a school depends on that. Unfortunately, quite often, rural public schools have SGB and school management teams that have no capacity due to lack of education, leadership and managerial skills among the parents who are the majority. This is because majority of elected SGB members are school dropouts who did not get adequate education; although they receive training when they are elected to SGB. It has been reported that the department of education only provides limited initial training soon after the election of SGB which is not continuous (Heystek, 2004). As a result of inadequate training, the capacity of SGB and school management has a negative impact on the performance of many rural schools in South Africa. Mandlethu FET School is one of the schools which have performed very poorly for a long time. Therefore, the purpose of this investigation was to assess the capacity of the SGB and the school management of the Mandlethu FET School to support teaching and learning of mathematical literacy at the school, with the view of recommending the remedial measures, which will improve the overall school performance, and in particular the performance of mathematics and science subjects.

Mathematical literacy (ML) was introduced as a result of curriculum transformation after the adoption of the Constitution of the Republic of South Africa (Act 108 of 1996). One of the aims of the constitution was to "improve the quality of life of all citizens and free the potential of each person" (DOE, p4).The apartheid system of education was of poor quality thus resulted in very low levels of literacy and numeracy in the adult population of South Africa. The literature shows that South African learners fared very poorly in mathematical literacy tests when compared to their counterparts in other developed and developing countries (Howie, 2006). Mathematical Literacy (ML) in the Further Education and Training curriculum was mandatory for all learners of Grade 10 to12 who did not choose the subject Mathematics (Sidiropoulos, 2008). Christiansen (2006:10) claims that the two main reasons for introducing ML were to reach the Grade 12 school leavers without Mathematics, as well as the large number of learners who failed the subject each year. While Mathematics is not only a gateway subject to many disciplines, a citizen needs to have some form of mathematical literacy to be a productive independent member in the society (Nel, 2012).

The National Curriculum Statement Grades 10 to12 (general) mathematical literacy aims to develop a high level of knowledge and skills in learners and also sets up high expectations of what all South African learners can achieve. The aim of mathematical literacy is to produce a learners who "have access to, and succeed in, life-long education and training of good quality; demonstrate an ability to think logically and analytically, as well as holistically and laterally; and be able to transfer skills from familiar to unfamiliar situations" (DOE, 2003 p9)

The kind of educator that is envisaged is the educator who is qualified, competent, dedicated and caring. This educator should be able to fulfil the various roles outlined in the Norms and Standards for Educators, namely being a mediator of learning, an interpreter and designer of learning programmes and materials, a leader, an administrator and manager, a scholar, researcher and lifelong learner, a community member, a citizen and pastor, an assessor, and a subject specialist.

This educator is envisaged to provide a learner with opportunities that will develop:

- the ability to understand mathematical terminology and to make sense of numerical and spatial information communicated in tables, graphs, diagrams and texts.

- the use of basic mathematical skills in critically analysing situations and creatively solving everyday problems.

- A confident adult who will be able to relate to financial issues such as hire-purchase, mortgage bonds, and investments.

- the ability to read a map, follow timetables, estimate and calculate areas and volumes, and understand house plans and sewing patterns. Handle activities that require the efficient use of ratio and proportion that are encountered in everyday life situations.

- the learner to become a self-managing person, a contributing worker and a participating citizen in a developing democracy who is suited to the modern world. (DOE, 2003)

Furthermore the policy states that learners proceeding to Higher Education institutions will have acquired a mathematical literacy that will enable them to deal effectively with mathematically-related requirements in disciplines such as the social and life sciences. The policy cautions that Mathematical Literacy should not be taken by those learners who intend to study disciplines which are mathematically based, such as the natural sciences or engineering. This however, is a disadvantage for learners who if not well informed, may find themselves at tertiary institutions only to 
discover that they may not register for natural sciences or engineering. The next section is the methodology of the study

\section{Methodology}

The study was a case study of Mandlethu FET School in Mpumalanga province and used a mixed method research design. Qualitative and quantitative data was collected. The case study was selected in order to create a baseline for schools in Nkangala District Municipality of Mpumalanga Province. The school enrolment was about 253 learners; 9 educators; 1 admin clerk, 2 general assistants and 2 kitchen helpers as of 2012. It is located in a township about $76 \mathrm{~km}$ northeast of Pretoria and the majority of the people are Ndebele. All elected members of the SGB and the school management were identified as potential respondents. All school management members were invited for interview, but only two SGB members (the chairman and an ordinary member) were available. The school management team that was interviewed included the school principal, deputy principal, two Head of Departments (Languages, Commercial Sciences) and three senior educators.

A survey was conducted at Mandlethu FET School between April and May 2012. Face-to-face interviews were conducted using structured questionnaires. Two separate questionnaires for SGB and school management were used to capture responses during the interviews. The questionnaire for SGB and school management contained 36 and 40 questions, respectively. The questionnaire contained open ended, multiple choice and opposition questions. Appointments were made with the participants prior to the interviews. The interviews were conducted in the school boardroom. Two researchers were involved in interviewing each respondent where, one person was the interviewer and the other person was the scribe. Audio recorders were also used to assist scribes to capture the proceedings to improve reliability of data.

\subsection{Data analysis}

Data obtained from multiple choice and quantitative data was analysed using Statistical Package for Social Sciences (SPSS software version 16). Data obtained for open ended questions (qualitative date) was analyzed by coding and memoing (Babbie, 2010). The analytical procedures for qualitative data included seven (7) phases: (a) data organization; (b) data immersion; (c) generating categories and themes; (d) data coding; (e) offering interpretations through analytic memos; (f) searching for alternative understanding; and (g) writing of the report (Marshall \& Rossman, 2011).

\section{Findings}

\subsection{The demography of the school management}

The SMT consisted of six (6) members, the principal, deputy principal (also HOD for languages), two heads of department for commerce and science; and two senior educators. Sixty-seven percent of the SMT were females and 3\% were males. Their home languages were IsiNdebele (33.3\%), Sepedi (33.3\%) and Setswana (33.3\%). Their age groups ranged from 41 to 60 . Fifty percent of the SMT had university education and the other $50 \%$ had college education. Although the information shows that management was qualified and would be capable of running the school more efficiently, in reality all of them were trained as professional educators not managers responsible overseeing the teaching and learning of science subjects.

\subsection{Previous experience in school management}

Only one member indicated that she had previous experience in a similar position elsewhere for 1 year. The other 5 respondents said that they had no prior experience in school management before they were appointed to the positions at the Mandlethu FET School.

\subsection{The demography of the school governing body}

There were only 2 members of the SGB (the male chairman and one female ordinary member) who were available for the interview. They were from the same age group between 30 and 40 years. Both have been serving as SGB members for less than 5 years. They were of the same education level (college education. Both SGB members had children 
schooling at Mandlethu FET School.

\subsection{The role of the SGB at the Mandlethu FET School}

The SGB said that they were fully aware of their roles as elected at the school and reported that they were inducted and received further training. They described their roles as: to govern the school and its properties for example, school budget, teaching materials; maintain good relationships between educators and parents and between the school and educators; help the school to improve results; improve school infrastructure; supervise the feeding scheme at school to ensure that learners eat properly; discipline learners and educators; to prepare budgets for teaching materials and school development; and to ensure that everything at the school runs smoothly.

\subsection{The relationship between the SGB and management, educators, learners and parents}

The respondents reported that their relationship with the SMT was good because they discussed issues and reached consensus. They also said that their relationship with educators who lived close to the school was good, but with educators who lived far from the school it was not good. This was because of the role the SGB played in disciplining educators. Some educators felt threatened by the presence of SGB members in the premises. The SGB relationship with learners was sometimes unpleasant because the SGB members disciplined them. The relationship with parents was excellent, because they are the majority in the SGB and parents are supportive and willing to discipline their children.

\subsection{School finance and audit}

With regards to whether the school was audited by the provincial department of education, their responses were varied. Four respondents indicated that there were audits before and the outcomes were good, while two respondents said that there was never an audit at the school. The mixed responses may indicate lack of clear communication between members of school management.

Some respondents reported instances of delay of government funds and that the school raised funds through donations to compensate funds. Sometimes the school sent letters to companies to ask for donations. On the contrary, other respondents indicated that no fundraising ever took place, although learners were sometimes asked to donate whatever they could on selected Fridays, and parents were also asked to make contributions in addition to the sale of vegetables from the school garden to the community. Emanating from the above discussion, this is yet another illustration of lack of communication, where some respondents were less informed than others. Because the school is non-fee, there should be more visible provincial government support to ensure adequate resources. The school should liaise more with the provincial government for adequate support.

\subsection{School security}

Regarding the security situation at the school, two respondents indicated that there was adequate security at the school, while the other four respondents indicated that there was never adequate security. The four respondents also reported that the SMT frequently requested neighbours and support staff to help with the security.

The SMT said that the provincial department of education was responsible for providing security at the school. On the contrary, the SGB members said that it was the responsibility of the school principal. This response contradicted what the school management had said. These differences showed that the SGB and SMT do not engage with the school security issue.

\subsection{Improvement on school infrastructure, teaching and learning}

Concerning improvement on teaching and learning this included extra teaching sessions on Saturdays, outsourcing external educators to articulate topics that school educators were struggling with, increased pass rate for mathematics, better classroom environment, and the introduction of the feeding scheme. SGB respondents said that they obtained extra resources to improve the quality of education at the school from external donors such as Consol Company, who donated funds for computers, printers and other office requirements in 2011. They also said that government assistance was very little and it always came too late every year. As a result sometimes employed parents donated money to buy 
typing paper for the school.

\subsection{Handling of disciplinary issues for educators and learners}

Concerning how they dealt with disciplinary matters concerning educators and learners, it was reported that educators were governed by the Mpumalanga department of education and the principal was their supervisor who had to deal with their discipline. The principal was required to convene a meeting with the educator in the presence of the SGB to deal with any disciplinary issues. Learners were required to be at school by $7.00 \mathrm{am}$. The School Representative Council (SRC) president gives learners 15 extra minutes to arrive at school and then he locks the school gate. Late learners are disciplined by the SRC president, but if they were late more than twice, they would be required to go home and call their parents to come to school before disciplinary action was taken against their children. Learners could also phone their parents to come to school and if the parents were not available, learners had to stay home until they could come with their parents to school. The principal could also call parents to discuss the discipline of their children and also could ask parents to discipline their own children.

\subsection{Challenges facing the teaching and learning of Mathematical Literacy}

The SGB and school management respondents reported that the challenges in teaching and learning of ML and other science subjects at the school were more due to lack of resources such as: teaching aids and learning materials for ML subjects (standard textbooks, study guides, stationary); lack of skilled ML educators; lack of education excursions; lack of infrastructure (library); lack of collaboration among educators to improve their skills; demotivated ML learners; lack of parental support and motivation; low pass rates in science subjects compared with other school subjects; bad attitude towards mathematics ML and physical science; and poor attendance of meetings by SGB members.

However it was the responsibility of SGB to ensure that the department of education provided the school with all the resources required for teaching and learning (Bush and Heystek, 2003). The school seemed to have these challenges because the Mpumalanga provincial department of education did not provide the school with adequate support for teaching resources as required by SASA (1996) and the Education Law and Policy Handbook (RSA, 1999). It also showed lack of liaison between the school management, the SGB and the local circuit and curriculum manager. Mandlethu FET School is one of the schools that performed very poorly each year especially in science subjects. This raises the question of whether the circuit and curriculum manager are capable of picking up the problems or not? This could also be due to lack of capacity on the part of the school management to plan, budget and articulate school needs at SGB meetings as they are expected to do.

One of the major challenges reported above was that the school management believed that $\mathrm{ML}$ and science educators did not have adequate skills to articulate the curricula. The academic qualifications of the educators may also be contributing to their lack of skills for teaching ML and science subjects, because $80 \%$ of the educators had national diplomas which they obtained under the old curriculum, while they are expected to teach the new curriculum. Some of the educators were not trained to specifically teach the subject, but they were required to teach it. This was reported to be an endemic problem in most South African schools, where the majority of educators are qualified as professional educators but their training in mathematics and Science subjects has been reported to be inadequate (Mangena, 2001).

\subsection{Assistance required for improving teaching and learning of science subjects}

Both the SGB and school management respondents said the type of assistance needed to improve teaching and learning of ML was: (a) funds to purchase teaching and learning materials (textbooks, stationary, study guides, etc.), (b) funds to outsource subject experts to help with teaching of science subjects, (c) external educators; (e) vocational subjects; (f) additional educators; $(\mathrm{g}$ ) computer skills and courses in management for improvement; ( $h$ ) adequate security, (i) a strong fence around the school; (j) computers for educators to do their work; (k) computer laboratory for learners; and (I) an operational library. The response shows that they do not have confidence in their ML educators.

However; this may demoralize ML educators because they may perceive the acquisition of experts as jeopardising their jobs. Hiring of temporary educators to teach during school holidays and weekends is seen by the SGB as an antidote to help teaching and learning of science subjects, but there are no funds to pay extra educators. It is the responsibility of the school to employ additional educators in addition to those allocated by department of education as long as the school can raise funds to pay for the additional educators (RSA, 1996a). The SGB is expected to raise funds 
to improve the quality of education at the school (Bush and Heystek, 2003).

The School management and SGB respondents further reported that they needed short courses, and training workshops in management to help them to improve their managerial skills.

\subsection{The school administration and the governing body (discussion)}

This study found out poor communication between school management team and the School Governing Body (SGB) at Mandlethu FET School. Poor communication was noted from contradicting responses given by the school management and SGB on issues regarding their responsibilities, school security, and finance and school meetings. The SGB comprises of school parents (who are the majority), educators, learners and the principal who is the ex-officio (Karlsson, 2002; RSA, 1996: section 23; Van Wyk, 2004); while the school management includes the principal, deputy principal and heads of departments or senior educators (Heystek, 2004). The rationale for the establishment of democratic structures of school governance is to ensure that educators, parents, learners and non-teaching staff actively participated in the governance and management of schools with a view of providing the right environment for teaching and learning (Van Wyk, 2004). It was then quite essential that the school administration and SGB communicated well on school matters for smooth running of the school. As SGB the comprises of school parents who were the majority, it is through SGB that many parents can be mobilized to help their learners at home by giving them more time to work on school assignments and encourage them to study.

The School management and SGB respondents reported that they needed short courses, and training workshops in management to help them to improve their managerial skills. Such an appeal from members is commendable as lack of managerial skills and experience to executive SGB roles was identified as a major problem in South Africa public schools (Van Wyk, 2004). SGB members in South Africa are only provided with limited initial training when they are elected (Heystek, 2004 ibid.) and the same applied to principals who were appointed as leaders on the basis of their teaching records rather than their leadership skills and received very limited induction and support to perform their roles (Bush and Oduro, 2006). SGB respondents emphasised more about honoraria payments, personal computers and training workshops for financial management skills, among the things they needed to enable them to perform much better.

\section{Recommendations}

From the research findings, the following are recommended for the improvement of governance and management at Mandlethu FET School to improve the support they would give in the teaching and learning of ML;

- induction and mentorship of members of the school management and SGB on their roles at the school;

- encourage proper communication among members of school management and SGB to ensure that every member participates and contributes to all decisions regarding governance and management of the school;

- emphasize the importance of discussing school issues in meetings;

- review school admission policy;

- liaise with circuit and curriculum manager regularly;

- liaise with the provincial department of education to ensure that school needs are communicated more efficiently;

- allocate roles to HOD according to skills and subjects expertise;

- the SGB has to initiate fund raising to employ the required skilled educators and acquire science teaching materials;

- the SGB and school management have to improve school security;

- the SGB has to compile annual budgets and financial reports for submission to the provincial department of education for the department to release funds timely;

\section{Conclusion}

The school management should translate these suggestions into concrete plans and forward them to SGB for inclusion in strategic planning and budgeting for the next financial year. The need for extra teaching sessions is perceived by the SGB as an antidote to lack of skills by science educators. It raises a major concern that educators are either not using the time allocated for teaching efficiently or the time allocated is not enough. The introduction of vocational subjects such 
as typing, arts etc. has also been suggested as an alternative for learners who are struggling with $\mathrm{ML}$ and science subjects.

The school management indicated that they perceived the need for a stipend or allowance for SGB members to encourage them to participate fully in school activities. However, the SGB affiliation is voluntary for parents whose children attend the school. This is a concern if SGB members are not participating fully in activities involving their children. Although school management perceived that honoraria payments as a way to encourage SGB members to participate fully in school activities elected SGB members should be people who have interests in school activities (Bush and Heystek, 2003). Obviously if SGB members need honoraria payments to participate fully in school activities, then the school has elected wrong members to serve on the SGB. Poor communication between school management and SGB; among members of school management stood out as major problems at Mandlethu FET School.

Furthermore, the school management does not understand the role of SGB at the school because they never mentioned anywhere that they have ever submitted their challenges in writing to the SGB for escalation to the provincial department of education. This could be attributed to the fact that the school management were trained as educators not managers. They indicated that they needed training in management to sharpen their managerial skills. That means currently they do not have the ability to support the teaching and learning of science subjects at the school as indicated in the report, until they are properly trained as managers. The school management in consultation with the SGB and the Department of Basic Education should find ways of inducting teachers in topics that the teachers found difficult to teach including recruiting qualified teachers to teach mathematical literacy.

\section{References}

Babbie, E. (2010). The practice of social research. 12th ed. Wadsworth: Cengage Learning.

Bush, T. \& Heystek, J. (2003). School governance in the new South Africa. Journal of International Education, 33 (2): 127-138.

Bush, T. \& Oduro, G.K.T. (2006). New principals in Africa: preparation, induction and practice. Journal of Educational Administration, 44(4): 359-375.

Christiansen, I.M. (2006). Mathematical Literacy as a School Subject: Failing the Progressive Vision? Pythagoras, 64, 6-13.

Department of Education (2003). National Curriculum Statement Grades 10-12(General) Mathematical Literacy, Pretoria.

Heystek, J. (2004). School governing bodies: the principal's burden or the light of his/her life? South African Journal of Education, 24 (4): 308-312.

Howie, S. (2006). Multi-level factors affecting the performance of South African secondary school pupils in mathematics. In Howie, S., \& Plomp, T. (Eds).(2006). Contexts of Learning Mathematics and Science: Lessons learned from TIMSS (pp. 34-45). London: Routledgefalmer

Karlsson, J. (2002). The role of democratic governing bodies in South African schools. Comparative Education, 33(2): 327-336.

Marshall, C. and Rossman, G.B. (2011). Designing qualitative research. 5th ed. Los Angeles: Sage Publications.

Nel, B. (2012). Transformation of teacher identity through a Mathematical Literacy re-skilling programme South African Journal of Education 32(2): 22-31.

Republic of South Africa (1996). South African schools Act No. 84 of 1996: Section 16. Pretoria: Government Printers.

Sidiropoulos, H. (2008). The implementation of a mandatory curriculum in South Africa. Available: http:/lupetd.up.ac.za/thesis/submitted letd-06032008-115730/unrestricted/01chapters1-2.pdf, retrieved 07 10/2012

Sowetan (2012 October, 05) Zuma thanks teachers. Available: http://www.sowetanlive.co.za/news/2012/10/05/zuma-thanks-teachers; retrieved 08/10/2012

Van Wyk, N. (2004). School governing bodies: the experiences of South African educators. South African Journal of Education, 24(1): 49-54. 
